\title{
Sustratos de hierofanías, arquetipos y rituales en el cine de Gutiérrez Aragón
}

\section{Substrates of hierophanies, archetypes and rituals in the films of Gutiérrez Aragón}

\author{
José Luis Sánchez Noriega \\ Universidad Complutense de Madrid \\ noriega@ucm.es \\ http://orcid.org/0000-0002-1266-300X
}

\section{Resumen:}

Se propone una aproximación nueva al cine de Manuel Gutiérrez Aragón, hasta ahora estudiado desde perspectivas políticas o, sobre todo, literarias y mitológicas con categorías como magia, fabulación, figuras heroicas, etc. Se realiza una hermenéutica de esa filmografía desde formas de lo sagrado establecidas por la fenomenología de las religiones que sobresalen particularmente en las películas Camada negra, El corazón del bosque, Demonios en el jardín, La mitad del cielo y Todos estamos invitados: el bosque y el árbol sagrado, el arquetipo de la Madre nutricia y el ritual de la comida. Ello permite considerar cómo en un medio de tan solo cien años, como es el cine, también tienen lugar hierofanías, arquetipos y rituales de la milenaria historia de las religiones. Contrasta este sustrato de religiosidad pagana de raíces telúricas y vínculos con las deidades agrarias con el contemporáneo catolicismo español.

\begin{abstract}
:
It proposes a new approach to the cinema of Manuel Gutiérrez Aragón, until now studied from political perspectives or, above all, literary and mythological with categories such as magic, fabulation, heroic figures, etc. A hermeneutics of that filmography is made from sacred forms established by the phenomenology of religions that stand out particularly in the films Camada negra, El corazón del bosque, Demonios en el jardín, La mitad del cielo and Todos estamos invitados: the forest and the sacred tree, the archetype of the nurturing Mother and the ritual of food. This allows us to consider how, in a medium of just one hundred years, such as cinema, there are also hierophanies, archetypes and rituals of the millennial history of religions. Contrast this substrate of pagan religiosity with telluric roots and links with agrarian deities with contemporary Spanish Catholicism.
\end{abstract}

Palabras clave: Cine español; Gutiérrez Aragón; árbol sagrado; madre nutricia; comida.

Keywords: Spanish cinema; Gutiérrez Aragón; sacred tree; nurturing mother; food. 


\section{Introducción ${ }^{1}$}

El cine de un país con una tradición religiosa tan fuerte como el catolicismo en España parece que necesariamente tiene un discurso sobre la religión, aunque no siempre sea explícito. Creo que, al respecto, se pueden esquematizar tres líneas o posiciones entre los cineastas. Una primera es la del cine confesional que tiene fuerza durante el franquismo (Rafael Gil, Vicente Escrivá) y resurge en los últimos años con trabajos como los de Pablo Moreno Un Dios prohibido, Poveda, Luz de soledad, Red de libertad y Claret, filmadas entre 2013 y 2020, aunque ocupe un lugar marginal, meramente testimonial en su estética y difusión. Una segunda y más interesante es la representada por cineastas como Luis Buñuel, Pedro Almodóvar o Francisco Regueiro, para quienes las creencias y la moral católica, los personajes de la Iglesia, la educación religiosa o costumbres de religiosidad popular siempre resultan relevantes, aunque susciten sentimientos opuestos, pues coexisten el rechazo y hasta la respuesta anticlerical con cierta fascinación por la estética de la liturgia y la religiosidad popular. En una tercera línea, más distantes hacia la religión y con sensibilidades muy variadas, se encuentran la mayoría de los cineastas, cuyo cine puede ignorar por completo los contenidos religiosos, mostrarlos episódicamente de forma más o menos crítica o sustituirlos por formas secularizadas o equivalentes en la formulación de un sentido y una visión del mundo, una ética personal o social, o rituales y liturgias laicas.

En esa tercera posición se ubica el cine de Manuel Gutiérrez Aragón (Torrelavega, Cantabria, 1942), a quien el catolicismo no interpela hasta el punto de verse retado a reaccionar ante él. La mayoría de los estudiosos sobre su filmografía con Heredero (2004) y Molina Foix (2003) a la cabeza- abunda en la dimensión mitológica de los relatos, en su carácter alegórico o su valor de recreación de cuentos de hadas, dando cuenta de los actantes que responden a figuras literarias establecidas (singularmente el traidor y el héroe) y de las visiones menos factuales de la realidad como la fabulación, la fantasía, la magia o la memoria emocional.

1 Investigación financiada por el proyecto Desplazamientos, emergencias y nuevos sujetos sociales en el cine español (1996-2011) (I+D+i RTI2018-095898-B-Ioo), Ministerio de Ciencia, Innovación y Universidades. 
Esta acertada perspectiva no es incompatible con la que se desarrolla aquí, que es una más específica relación de esas películas con la religión o, si se prefiere, una indagación en la dimensión 'religiosa' -adjetivo entrecomillado por necesariamente vago e indefinido- del cine de Gutiérrez Aragón. Lo religioso ha adoptado formas muy diversas a lo largo de milenios, incluso aparentemente contradictorias, como las religiones que niegan la existencia de un Dios creador (budismo no teísta); en el presente, hay religiosidades que adoptan otros nombres o se ubican en otros ámbitos (deporte, vida natural, afición musical, etc.), habitualmente más perecederas, aunque mantienen un sistema de creencias, rituales específicos, vestidos o símbolos identificativos, prácticas establecidas, grupos de referencia o líderes carismáticos propios de la religión.

Esto nos exige dejar en segundo plano las habituales herramientas del análisis fílmico -textual, semiológico, estructuralista o cualquier otra tradicióndesarrollado a partir de los años setenta. Optamos por una metodología distinta y poco habitual en los estudios fílmicos al basarnos en las reflexiones más pertinentes de la fenomenología, psicología, filosofía o historia de las religiones comparadas, particularmente algunas desarrolladas por Eliade (1981), Frazer (2011) o Neumann (2009). A esta opción subyace el presupuesto -de tradición junguiana- de que las manifestaciones literarias, culturales, artísticas, filosóficas o religiosas poseen o vienen generadas por un trasfondo común o unas interconexiones que configuran lo esencial e intemporal en todos los seres humanos. Dicho muy esquemáticamente y en un sentido muy amplio: la religión en cuanto respuesta al misterio que resulta incomprensible (de la belleza, existencia, humanidad, más allá...) es una dimensión antropológica indeleble.

Nos van a interesar más textos fílmicos que no se refieren directamente a la religión pues, de hecho, sus películas con historias o secuencias inequívocamente religiosas son, en realidad, películas políticas en tanto en los sucesos narrados se destaca la dimensión ideológica y el contexto histórico de polarización política, como se aprecia de forma evidente en Visionarios (2001), donde las apariciones de la Virgen en Ezkioga y sus profecías sobre la Guerra Civil y el fin de la República forman parte del discurso de reacción de la derecha conservadora frente a las políticas de profundización democrática de la República. Se produce en ellas una legitimación católica del fascismo político que pervive hasta el final 
del franquismo, como vemos en Camada negra (1977) con la simbiosis de coro religioso y banda fascista en un mismo grupo, claramente identificado con los Guerrilleros de Cristo Rey. En otros casos, se trata de elementos o fragmentos más circunstanciales, donde la presencia de la religión se limita a la práctica religiosa -por ejemplo, en las secuencias de asistencia a misa dominical de Demonios en el jardín (1982)- con un valor descriptivo para caracterizar el nacionalcatolicismo del régimen de Franco; o aborda la ambigüedad de la Iglesia ante el terrorismo de ETA (o la irresuelta contradicción de acoger en los templos a los asesinos), como en Todos estamos invitados (2008), donde se muestra a los terroristas como católicos practicantes.

Este cine otorga una dimensión de cierta trascendencia no deísta (mágica, espiritual, arquetípica...) a espacios, objetos y figuras muy presentes en las formas más ancestrales de religiosidad, como nos hace ver Eliade (1981). Tres son las formas que, al respecto, parecen más relevantes en el cine de Gutiérrez Aragón: el bosque y el árbol sagrado, el arquetipo de la Madre nutricia y el ritual de la comida. No se trata de una forzada lectura religiosa de elementos profanos - con todo lo legítimo que, por otra parte, pudiera ser-, sino de subrayar las raíces fenoménicas de elementos recurrentes en esa filmografía y su vinculación profunda con las formas más ancestrales de cultos y creencias religiosas, incluso cuando se manifiesten en contextos completamente secularizados.

Esos tres elementos mantienen una relación estrecha que los fenomenólogos han puesto de relieve y se puede establecer perfectamente la secuencia árbol-madrenutricia-alimento. En una formulación más directa, el árbol se vincula a las deidades agrarias femeninas que proporcionan alimento; así, en la iconografía del antiguo Egipto aparece el sicomoro o la palmera datilera como encarnación de la diosa Hathor que provee de alimento a las almas. La secuencia adquiere complejidad si tenemos en cuenta que Osiris es un dios árbol, asimismo nacido de un árbol, y la madera posee la dualidad de cuna y sarcófago (etimológicamente “devorador de carne”), esto es, de divinidad engendradora de vida, pero también 
de muerte (Neumann, 2009, pp. 239-241)². Para el viaje a la otra vida, el cadáver se coloca en postura osiríaca, con los brazos cruzados sobre el pecho. En el caso de Camada negra, el trasfondo religioso es explícito en el arquetipo de la Madre, ya que la religión se convierte en argumento legitimador de la violencia auspiciada por ella; y en La mitad del cielo el árbol se vincula directamente con la figura de la Madre y también a través de la madera de los zuecos, que adquieren valor simbólico cuando pasan de la bisabuela a la nieta del mismo nombre (Olvido) y con las mismas cualidades de videncia.

\section{El bosque y el árbol sagrado}

Como, entre otros, ha puesto de relieve Agustín Gómez (2013 y 2019), en este cine el espacio natural, el paisaje, adquiere protagonismo al trascender el mero marco o contenedor para devenir lugar de la acción dramática, frecuentemente caracterizado con la impronta de sucesos históricos. La Naturaleza aparece en este cine como un espacio sobrecogedor que se impone por su grandiosidad a cualquier mirada, como muestran los planos generales de montañas y bosques con que suelen iniciarse las secuencias de presentación en varios títulos y, en general, la forma de filmar con cierta distancia, preservando el misterio del monte gracias a la niebla y a los sonidos enigmáticos que impiden un espectador omnividente y omnisciente. La presencia del bosque en las primeras películas tiene la hondura de la experiencia autobiográfica, indeleble al cabo de los años:

El origen de esta historia [El corazón del bosque, 1978] se encuentra, evidentemente, en las entrañas de un bosque, pero su nacimiento más consciente es producto de dos maneras de acercarme a ese ámbito. Una pertenece a la dimensión mítica y está relacionada con mis visitas al bosque en la moto de mi padre, con la presencia física de la vegetación, las sombras que se esconden entre los árboles, los ecos de una cierta literatura cántabra y asturiana (las hadas, los trasgos, etc.) y hasta con las leyendas sobre los maquis que se escondían en su interior (Manuel Gutiérrez Aragón en Heredero 1998b, p. 74).

2 En Feroz (1984), el hombre-oso es ocultado en un ataúd de madera vista que, por un accidente, sirve para la navegación por el río, con lo que a la transformación de la carne (cuerpo, identidad) de ese personaje se suma la mitología del nacimiento de las aguas. 
La hermenéutica del bosque en este cine requiere recordar algunas reflexiones básicas de la fenomenología de las religiones.

Las formas más primitivas de religiosidad tienen que ver con el sobrecogimiento de los seres humanos ante el misterio y lo sagrado, percibido de forma muy inmediata en el carácter inabarcable e inescrutable del Cosmos. Los dioses uránicos y las hierofanías solares y lunares presentan variadas y recurrentes acepciones y rituales a lo largo de culturas milenarias en todo el mundo. Como señala Eliade (1981), los cultos a la Madre Tierra tienen su raíz en la divinidad telúrica, luego manifestada en montañas, bosques, aguas o vegetación como formas de existencia que revelan el sustrato sagrado. Esa condición sacra se plasma en las deidades agrarias y en los cultos de fertilidad que ven en la regeneración de la Naturaleza y en los ciclos anuales de la agricultura un potencial de creación de vida similar a la maternidad: "Una de las primeras teofanías de la tierra como tal, sobre todo de la tierra como substrato telúrico y profundidad ctónica, ha sido su maternidad, su inagotable capacidad de dar fruto" (Eliade, 1981, p. 256).

El bosque es lugar sagrado en cuanto compendio de las hierofanías telúricas de las piedras sagradas (cratofanías, megalitos), vegetales medicinales y terapéuticos (hierbas, cortezas, raíces), aguas de fertilidad (manantiales, grutas) y, sobre todo, porque se configura a partir del árbol, uno de los elementos más versátiles en las epifanías. Eliade (1981) dedica un extenso capítulo de su estudio sobre la morfología de lo sagrado al árbol cuya inabarcable proliferación sintetiza en las siguientes tipos: $a$ ) el conjunto de piedra-árbol-altar, que constituye un microcosmos efectivo; b) el árbol-imagen del cosmos; c) el árbol-teofanía cósmica; d) el árbol-símbolo de la vida, de la fecundidad inagotable, de la realidad absoluta, relacionado con la gran diosa o el simbolismo acuático e identificado con la fuente de la inmortalidad; e) el árbol-centro del mundo y soporte del universo; $f$ ) vínculos místicos entre los árboles y los hombres; y $g$ ) el árbol-símbolo de la resurrección de la vegetación, de la primavera y de la regeneración del año.

Resulta pertinente la reflexión de Frazer (2011, pp. 70-77) sobre el árbol, que hace prosperar las cosechas y los rebaños, además de procurar hijos a las mujeres 
bendecidas, de ahí las costumbres del árbol de mayo que se transporta del bosque a la aldea en una celebración festiva por sus propiedades beneficiosas para la comunidad; el nacimiento del Sol en el solsticio de invierno tiene su simbolización con el árbol de Navidad. Estos y otros muchos ejemplos otorgan al árbol un sesgo materno que alumbra la vida, aunque también se vincula a la muerte o, mejor, a la inmortalidad: el símbolo por excelencia del cristianismo la cruz- es una esquematización de la figura del árbol; además, se subraya la naturaleza de su origen en la expresión el árbol de la cruz que vincula la muerte sacrificial a la nueva vida de la inmortalidad: "El colgado del árbol, el hijo de la madre del árbol, es sin duda muerto por ésta, pero a cambio ella le hace entrega de la inmortalidad elevándolo a su cielo imperecedero, donde él participa de ella como la dadora de sabiduría” (Neumann, 2009, p. 250).

El misterio del bosque y la fertilidad del árbol están muy presentes en El corazón del bosque, aunque ese espacio natural sirva para una historia de abandono, soledad, supervivencia, miedo, enfermedad y derrota, como corresponde al ocaso de la lucha guerrillera antifranquista. El refugio en el bosque lleva a una mimetización e identificación de los maquis con los seres del espacio natural - “A veces los personajes sólo son espíritus del bosque" dice el cineasta (Martínez Torres, 1992, p. 115)- como refleja la imitación del canto de los pájaros, las referencias a los animales y la protección de todo tipo de plantas. Se trata de un espacio donde el tiempo incierto y los cambios de luz, vegetación o condiciones atmosféricas lo convierten casi en personaje, con una dimensión fantasmática siempre inquietante, como ha observado Gómez (2013)3.

3 Carlos F. Heredero (1998b, p. 50) resume así ese aspecto: “Este bosque [de El corazón del bosque] vive en la pantalla con una fisicidad y una rugosidad, una presencia arbórea y una densidad lumínica que no llegaba a tener en aquella primera película [Habla, mudita]: aquí estamos dentro de un espacio realista y mágico a la vez, descrito por Gutiérrez Aragón con pinceladas casi antropológicas, habitado por una galería de personajes que entran y salen de las imágenes con cierto aire fantasmal, pero dejando entrever -al mismo tiempo- una entrañable encarnadura humana, hecha de dolor y silencio a partes iguales". En un sentido convergente, Molina Foix (2003, p. 70) también da cuenta de la personalidad del bosque y se refiere a un fragmento de esta película como "un poema en imágenes, escrito en un verso que solo podíamos llamar libre, pues aunque se inserta con toda verosimilitud en la línea del relato, sus palabras, sus concatenaciones visuales, no describen ni reflejan ni ayudan al progreso de la peripecia; hablan en el más bello lenguaje figurado de la respiración del bosque, de sus cualidades y sombras, de una cresta montañosa con un refugio en la cima, del ruido de las ramas quebradas y el canto de los pájaros sorprendidos.” 
La Naturaleza resulta ambivalente, aunque muestra su faceta más desabrida por el aislamiento de la civilización y el acoso que sufre el Andarín, deteriorado por la renuncia a los ideales de la lucha y la enfermedad. De esa ambivalencia dan cuenta los animales que muestran la abundancia del alimento (vacas que pierden leche), la fuerza amenazadora (toro con los ojos vendados para que no embista) y la indefinida relación de comunión (o unión sexual) con el caballo o yegua del guardia. Pese a todo, el bosque es el único refugio del guerrillero, la única posibilidad de supervivencia; y en él adquiere protagonismo el árbol maternal situado, muy acertadamente, en el centro del elocuente cartel de Iván Zulueta acogiendo a los personajes: Juan y Amparo protegidos por sus gruesas ramas en un abrazo y el Andarín tumbado a los pies del tronco. Del árbol se subraya la función simbólica de regeneración vital al servir para ocultar las medicinas, lo que se potencia con el tronco horadado que se aproxima a la figura de la gruta o cueva, espacio sagrado de manantiales milagrosos y aguas terapéuticas en las hierofanías ancestrales (Eliade, 1981, p. 212); entre la maleza del bosque se ocultan los alimentos que la gente deja para los maquis, con lo que se subraya la dimensión nutricia del árbol-bosque.

Si el deterioro del Andarín se puede ver en clave de animalización -"la enfermedad de la piel empezó a comerle la cara y todo, chillaba como un bicho... es como un bicho" explica el camarada a Juan- el final lleva a una vegetalización -Pérez Perucha habla de la transformación simbólica del guerrillero en árbol4- o incluso a una mineralización con su regreso al humus y transformación en polvo (tierra), según la fórmula penitencial de Cuaresma. En su agonía, el Andarín adopta una posición fetal como un retorno a la Madre Tierra regeneradora, pues las inhumaciones de cuerpos que adoptan figuras similares a las del embrión responden a la creencia en una vuelta a la vida5. Poco antes, un enorme tocón -

4 "Y es que un árbol, y no en otra cosa se ha convertido, iconográficamente hablando, el rugoso guerrillero interpretado por Luis Politi, no puede ser eliminado: el bosque está cubierto por árboles (guerrilleros) que se alimentan de la humedad y se protegen bajo las nieblas. El guerrillero, pues, ha perdido sus señas de identidad individual y se ha disuelto en el mito." (en Talens y Zunzunegui, eds., 2007, p. 176).

5 Eliade (1981, p. 263) realiza una precisión muy valiosa para nuestra hermenéutica al indicar que "Por el binomio homo-humus no ha de entenderse que el hombre es tierra porque es mortal; el sentido es otro: es que el hombre ha podido tener vida por venir de la tierra, porque ha nacido de -y vuelve a- la Tierra Mater". 
testimonio del árbol amputado, destruido- por delante del cual pasan Juan y el Andarín, unidos por una soga, preludia el final de este último.

En el primer largometraje del cineasta cántabro, Habla, mudita (1973) el bosque y la montaña servían para el contraste natura/cultura que vertebra todo el relato, lo que también sucede, aunque en menor medida, en Demonios en el jardín (1982) al oponer la casa de la indómita Ángela en plena naturaleza a la de la familia de su marido, en medio del pueblo. Por el contrario, en Feroz (1984) la misma dualidad se plasma de forma más irónica -diríase que deliberadamente contra toda mitología - al oponer la situación del protagonista en el bosque (con figura humana pero carente del lenguaje) y en la ciudad, donde se muestra como animal que habla. En todo caso, ciudad y bosque aparecen como espacios incompatibles para ese hombre-oso, que es devuelto al bosque tras el inútil intento de hominización, y hay que subrayar la austeridad del lenguaje hablado, los sonidos de la Naturaleza y la incomunicación y soledad humanas en amplios segmentos de esos títulos y en la citada El corazón del bosque: diríase que el bosque posee su orden y sus leyes que desbaratan la superioridad de la civilización y empequeñecen a los seres humanos, desorientados y aislados en la profusa vegetación del monte. Por otra parte, la dimensión mitológica del bosque está presente en cuanto deviene centro del mundo con las hierofanías marianas de Visionarios. En otros filmes, el bosque presenta un tratamiento bien distinto; lugar de caza (frustrante) para el jerarca franquista y refugio del furtivismo y de transgresión de la moral sexual dominante en Furtivos (1975), dirigida por José Luis Borau con guion de éste y de Gutiérrez Aragón; aparece como espacio ambivalente en Todos estamos invitados, pues sirve para el entrenamiento con armas del grupo terrorista al tiempo que otorga su alimento en un contexto terapéutico (recolección de hongos por Francesca y Josu Jon).

La pradera, el maizal y las montañas vecinas al bosque son espacios de fecundidad agropecuaria. La vaca es animal sagrado en varias civilizaciones a lo largo de los milenios, de lo que queda constancia singularmente en Egipto e India; se vincula a las deidades de fertilidad, como queda reflejado en el Atharva Veda "los dioses viven de la vaca y los hombres también; la vaca se ha convertido en este universo, tan vasto como el imperio del sol" (Eliade, 1981, p. 106). La disputa por una novilla es el origen del conflicto de La vida que te espera (2004), drama 
ambientado en los valles pasiegos donde el éxito de la supervivencia de unas hijas ante el autoritarismo del padre se escenifica en un concurso de vacas, admiradas como auténticos tótems entre los ganaderos; no extraña, entonces, la reacción airada del padre de Rosa (La mitad del cielo), corriendo tras sus hijas con un hacha tras haber intoxicado a las vacas con levadura de cerveza. Un toro de significación similar al citado de los ojos tapados aparece al inicio de Demonios en el jardín, como fuerza bruta y salvaje que amenaza la celebración de una boda; su presencia real y la congruencia con el marco espaciotemporal de la historia narrativa no excluye la dimensión mitológica o su condición de proyección onírica del subconsciente, pues, como indica el director, "[e]l toro es el temor que hay al otro lado del sueño, algo irracional que no depende de ti. Es la pesadilla de ese niño que vive en una atmósfera real, con unos parientes reales, pero que al otro lado del sueño, ve algo que le persigue, un toro. En este caso es un toro real pero tiene la voluntad de ser un toro de pesadilla” (Payán y López, 1985, p. 91). De hecho, el toro filmado a contraluz entrando en la iglesia donde se celebra la boda posee una lectura alegórica evidente: la irrupción de la fuerza indómita e instintiva del sexo desbarata la formalización de las relaciones sexuales en la institución matrimonial.

\section{El arquetipo de la Madre nutricia}

Como queda apuntado más arriba, uno de los rasgos más comunes en las religiosidades de la Naturaleza es su valor regenerador: la condición fértil de piedras, árboles, ríos o grutas se revalida con las deidades agrarias, que en buena medida poseen características luego atribuidas al arquetipo de la Madre nutricia. Son innumerables las simbolizaciones de la fecundidad de la tierra que, además, posee, en algunos casos, un carácter bisexuado, tanto en los nacimientos culturas donde se da a luz en el suelo, orígenes ubicados en grutas o montañas, héroes nacidos en el agua, recién nacidos desnudos colocados en tierra- como ante el riesgo de muerte (colocar al enfermo en el suelo) o en los ritos funerarios, con la ya citada inhumación del cuerpo en posición fetal o el enterramiento de niños en sociedades donde los adultos son incinerados. 
La fertilidad y capacidad para otorgar vida de las diosas de la agricultura se transfiere en el monoteísmo más depurado a la Madre por excelencia en el cristianismo, la Virgen María, cuyo mayor título es Madre de Dios; por ello son recurrentes sus hierofanías telúricas, sus apariciones en espacios sagrados precristianos o de fuerte carga simbólica ${ }^{6}$. En la primera secuencia de Feroz se evocan las apariciones de la Virgen en El Escorial que comienzan poco antes (1981) en un episodio donde hay una imagen de la Virgen en la copa de un árbol; también en Visionarios se rememora la aparición de la Virgen en Ezkioga en un espacio rodeado de árboles.

La figura de la Madre nutricia es compatible con la condición antiheroica o antagonista como aparece en personajes centrales de Furtivos, Camada negra y Demonios en el jardín que, además, ostentan su poder en ausencia significativa de un varón. Martina (Lola Gaos), la madre de Furtivos, se caracteriza como ama de cría del Gobernador civil quien se convierte en hermano de leche de Ángel, el hijo biológico que sufre a esa madre castradora y controladora, que lo ha reprimido manteniéndolo como niño (secuencia en que lo desnuda y baña). Ante esa madre tan represora como preocupada por la comida y el alimento -trasunto del paternalismo franquista- se rebela Ángel cuando la expulsa de la cama para poder llevar a la novia Milagros y, más tarde y de forma definitiva, cuando comete el asesinato liberador.

En el centro de Camada negra está Blanca, cabeza de familia al tiempo que líder de grupo fascista; es la Madre nutriente y líquido amniótico que alimenta el embrión totalitario definido por tres rasgos precisos: la familia concebida como matriarcado autoritario 7 y superprotector (rechazo de Blanca de su marido, órdenes tajantes a los hijos), la complicidad del Estado (condición de policía del hermano de Tatín) y la religiosidad gregaria que proporciona sentido de pertenencia y legitima la violencia de la banda (coro de canto gregoriano,

6 Apariciones de la Virgen en cuevas y/o manantiales (Lourdes, Covadonga, Banneux), árboles y bosques (Fátima, El Escorial, Virgen de Betania), peñas y montañas (Carmen, Guadalupe, Candelaria, Virgen de la Cabeza, Medjugorje, Ezkioga, Garabandal, Peña de Francia).

7 El protagonismo y hasta la preponderancia de la figura de Madre -cualquiera que sean las características de su estereotipo o su rol familiar o social específico- es compatible con una sociedad patriarcal, pues esa hegemonía, más que con el poder, tiene que ver con la forma de establecer la descendencia y de transmitir la propiedad, como ha observado Frazer (2011, pp. 300304) en pueblos tan distantes como los khasis en India y los de las islas Palaos en Filipinas. 
justificación de Blanca de la violencia purificadora como santa ira ${ }^{8}$, rezo de Tatín en el rito de iniciación con su hermano). En secuencias como el funeral del camarero se subraya la paradoja y la hipocresía de los grupos de ultraderecha incrustados en las esferas del poder simbólico (religioso) y político (policía); y en la cena de la familia-banda se plasma la simbiosis entre alimento físico y espiritual-político con el discurso de Blanca mientras sirve los platos.

Similar rol matriarcal desempeña Gloria (Encarna Paso), la madre -abuela para el niño desde cuya perspectiva se narra parte del relato- de Demonios en el jardín ante sus hijos, cuyas vidas controla incluso ejerciendo la violencia, como cuando les apalea llamándoles "caínes". En la tienda de comestibles se sitúa en el rincón de la caja registradora - cuyo funcionamiento enseña al niño-, concreción del poder económico, desde donde visualmente controla todo el espacio y vigila la clientela, sobre la que advierte al pequeño. Mantiene un comportamiento protector y castrador con su nieto, y ejerce de líder ideológica de la familia y hasta del pueblo, desde la atalaya privilegiada de la tienda, que es un espacio de socialización de primer orden en el ámbito rural; además, disponer de alimentos escasos en la posguerra le otorga el poder del cacique, pues genera fidelidades en función de la discrecionalidad con que vende bienes preciados producto del estraperlo. Asimismo, se subraya su condición de Madre nutricia por la relevancia de la comida en todo el relato y su presencia preeminente en la tienda de alimentación.

En contraste con estas tres películas de Madres antagonistas sintomáticas del peculiar matriarcado franquista, la figura de la Madre encarnada por la abuela Olvido (Margarita Lozano) en La mitad del cielo (1986) presenta otras características, arraigadas en la fenomenología y en la mitología, a la vez que queda afirmada su condición de Madre nutricia y la vinculación con la comida y su personaje encuentra prolongación en los de su nieta Rosa y su biznieta Olvido, lo que otorga una complejidad decisiva que va más allá del arquetipo. Olvido prepara con dulzura una rebanada con nata para Rosa, que ha estado ordeñando,

8 Refiriéndose a unos pintores dice Blanca "Esos venderían a su padre si supieran quién es: son todos los judíos del Templo, por eso hay que hacer lo que hizo el Señor, siendo Dios: la ira también puede ser santa, la santa ira". 
de manera que se vincula la comida al trabajo al tiempo que refuerza los lazos familiares; y más tarde le lleva botes de mermelada para el marido preso, en ausencia de palabras y muestras de afecto, las visitas de Rosa se limitan a proporcionar esa comida. La presentación al inicio del filme con las albarcas (zuecos) y su orina fecundadora de la tierra que se transforma en río apunta a la condición mitológica del personaje, lo que se revalida con sus poderes de adivinación (predice que el afilador morirá joven, averigua quién envenena a sus nietas, vaticina los resultados de una quiniela), con las pruebas iniciáticas a que somete a sus nietas y al marido de Rosa (peticiones y adivinanzas) o su conocimiento de las hierbas medicinales. Las albarcas participan del simbolismo del árbol por su condición de madera que se hinca en la tierra y que ejerce de cimiento para el tronco humano: además del plano inicial, el personaje de Olvido vuelve a ser presentado a partir de sus pies con albarcas en el sueño de la biznieta, quien se las calza ejemplificando la continuidad del arquetipo cuando falta la abuela9.

La vinculación de esta Madre a la tierra fértil y a los espacios de montaña no queda rota cuando viaja a la ciudad, en cuyo extrarradio encuentra lugares como el árbol sagrado junto al restaurante, el arroyo vecino de la autopista o donde dormir en un lecho de hojas secas. Más allá de la relación familiar, mantiene una relación maestra/discípula que se perpetúa simbólicamente en las apariciones post mortem con su biznieta Olvido, clara heredera de sus poderes: tiene sueños premonitorios, reta con adivinanzas, avala a Juan como pareja para su madre, aunque luego vaticina su pronta muerte. Con un fuerte carisma, el personaje de Rosa (Ángela Molina) posee cualidades de Madre nutricia desde el rol de ama de cría del bebé de don Pedro para quien prepara comida; además, al igual que su abuela desde muy pronto carece de marido.

\section{Tipos y funciones de los rituales de comida}

La recurrente presencia de la comida en la filmografía de Manuel Gutiérrez Aragón ha sido subrayada por todos los estudiosos, que han sabido apreciar en

9 También es el calzado empleado por los cazadores de El corazón del bosque. 
las secuencias de comidas y a la ingesta (o rechazo) de los alimentos valores simbólicos o un sentido metafórico (Martínez Torres, 1992; Heredero, 1998a y 1998b; Molina Foix, 2003) ${ }^{10}$. A veces, los alimentos forman parte del atrezo, sin que se muestre su consumo, como los puestos del mercado de La mitad del cielo, los chorizos colgados, los fruteros llenos y las verduras en las cocinas, y las despensas y desvanes con grano y comida para los animales del medio rural. En La mitad del cielo las relaciones de Rosa con varios personajes positivos para su devenir (don Pedro, Ramiro, el novio Juan, el funcionario y callado pretendiente Delgado) se establecen por la mediación simbólica de los alimentos; la posesión de destreza culinaria contrapone su personaje con el de sus hermanas; y don Pedro encuentra en la comida un postergado placer que alcanza valor sustitutivo del erótico. Es decir, que la comida resulta central en la construcción narrativa y la definición del ser y hacer de los personajes.

En muchas ocasiones la comida se integra en el filme con un tratamiento realista, como sucede con las comidas familiares, con secuencias ambientadas en las cocinas de las casas de pueblos o con la referencia a la diversidad y calidad de los alimentos españoles ${ }^{11}$; ello no significa renunciar a hermenéuticas que, al menos, han de tomar nota del valor de sinécdoque que las comidas presentan en bastantes ocasiones. Parece ecuánime la postura de Castellani (1987, p. 145) cuando en su estudio sobre las representaciones y roles de la comida en Demonios en el jardín llega a la conclusión de que el cineasta se aleja tanto del realismo documental como de la sinécdoque que otorgaría a cada elemento un valor simbólico. En todo caso, no se pueden negar los diversos valores rituales, como el propio cineasta reconoce ${ }^{12}$. La comida y ayuno rituales cuentan con tradiciones diversas en la historia de las religiones, desde las comidas de los sacerdotes en el sanctasanctórum de los templos egipcios a las reservas e ingestas periódicas en

10 Se puede consultar una primera versión de las reflexiones que siguen en Sánchez Noriega (2019).

11 Patatas coloradas, judías de El Barco, garbanzos de Fuentesaúco, lentejas de Salamanca, pimentón de Espinardo o el arroz de Calasparra citados en Demonios en el jardín; o la lista de quesos ("en el queso español jamás se pone el sol”) enunciada por el tendero de La mitad del cielo. 12 "En el proceso de civilización de nuestras sociedades es muy importante el rito de la comida. Las maneras de la mesa de las que habla Lévi-Strauss son tan importantes como el sexo. Y, sobre todo, las prohibiciones y obligaciones de comer, como por ejemplo, lo de la abstinencia y el ayuno." (en Martínez Torres, 1992, p. 79). 
distintos momentos del día en el hinduismo. Resulta absolutamente esencial en el cristianismo, donde la eucaristía es el centro raíz del culto católico ya que adquiere el sentido de unión mística de la persona con la divinidad mediante el acto simbólico de comer a Dios.

Los rituales de comida presentan tratamientos muy variados en el cine de Manuel Gutiérrez Aragón, desde alusiones episódicas a representaciones completas, con significaciones diversas. De su recurrencia y diversidad da cuenta Camada negra, donde aparecen cinco comidas con valores diferenciados: a) organización jerárquica del grupo bajo el dominio de la Madre nutricia, cuyo alimento metaforiza el aliento ideológico para las acciones criminales; b) la camaradería y cohesión de la banda fascista; c) el flirteo y la educación sentimental-sexual de Tatín; $d$ ) la cena homenaje de militantes izquierdistas boicoteada por Tatín seguida de atentado terrorista; y $e$ ) el rito de iniciación a la edad adulta ("hacerse hombre" = macho alfa fascista y violento) de Tatín en el seno de la familia-banda al tener que comer callos que le repugnan. Otras tantas comidas, con funciones también muy diversas, se plasman en La mitad del cielo.

Comidas proporcionadas por una Madre nutricia aparecen en los casos indicados más arriba de Furtivos, Camada negra, Demonios en el jardín y La mitad del cielo: el alimento resulta en ellos el rasgo esencial de esa figura dominante y de referencia para cuantos la rodean; predomina su capacidad para establecer jerarquías o afianzar dependencias de poder sobre la cualidad de abundancia y generosidad atribuida a la madre que alimenta a sus hijos sin esperar nada a cambio. Esta última característica posee la madre de Todos estamos invitados, que prepara el almuerzo a su hijo y que éste rechaza, metaforizando la opuesta cualidad moral de la madre generosa y el vástago terrorista. En el inicio de $L a$ mitad del cielo, la abuela Olvido prepara y comparte con su nieta Rosa un desayuno con rebanadas de nata de leche recién ordeñada, prefigurando la sintonía y homología entre ambos personajes.

La comida familiar o comunitaria está muy presente en esta filmografía; tiene carácter celebrativo y funciona como mecanismo de cohesión social y familiar (despedida de solteros de Amparo y Suso en El corazón del bosque, boda y celebración de la onomástica en Demonios en el jardín, banquete de finalización 
de la casa y boda de Juan en La mitad del cielo, convite de homenaje en Camada negra, cenas de Todos estamos invitados), sirve para la reforzar la identidad de un grupo (reunión de falangistas en La mitad del cielo), se utiliza como mecanismo de maniobra política (homenaje a Delgado en el restaurante de Rosa) o tiene la función de rearme moral de la secta o incluso deviene espacio humano donde planear acciones violentas (comida de los Guerrilleros de Cristo Rey presidido por la matriarca en Camada negra), aunque también puede ocultar el trasfondo cainita de la familia, como en el disparo que hiere a Juan en la comida final de Demonios en el jardín, o la falsa hermandad de la sociedad gastronómica en la que coinciden verdugos (abogado de etarras) y víctimas (Todos estamos invitados).

Manuel Gutiérrez Aragón firma como primer guionista de Las truchas (J. L. García Sánchez, 1978) donde la celebración de un banquete sirve para una radiografía del momento sociopolítico que vive la sociedad española en ese clima de cambio con los últimos estertores de la dictadura y la crisis a que se ven sometidos sus poderes, y la emergencia de un poder democrático, plasmado en las protestas en la calle y en las acciones de los trabajadores del restaurante. En ese contexto, la comida propiamente dicha, con el pescado podrido y un caldo elaborado a partir de desechos, es una alegoría con valor de síntesis del análisis social que se realiza a través de las microhistorias que configuran esta película mosaico.

La cuidadosa elección de pescados y mariscos de calidad y su elaboración en la sociedad gastronómica otorgan relevancia a la comida en Todos estamos invitados, título que bien puede interpretarse referido a la pertenencia a esa sociedad y, por extensión, a la exigencia de solidaridad con las víctimas del terrorismo o/y al compromiso con la pacificación del país. El tratamiento realista no es incompatible con el valor metonímico de la sociedad vasca que representa la mesa de la sociedad gastronómica con la hipocresía en el grupo de comensales en que participa el profesor amenazado por ETA.

La abundancia o calidad del alimento puede reflejar el estatus social, como sucede con la tienda en la posguerra de Demonios en el jardín; en esta película, esa vinculación entre comida-clase social también se muestra en la profesión de 
camarero de Franco que tiene su padre y que defrauda al niño Juanito. En La mitad del cielo se alternan los planos entre el banquete de los falangistas y la intoxicación de las hermanas de Rosa, mostrando la dualidad de los alimentos, que pueden generar vida o inocular muerte.

La comida puede ser percibida, en el recuerdo de la infancia, como forma de represión o exigencia como las lentejas rechazadas por la protagonista de Sonámbulos (1977)13 o la supuesta inapetencia de Juanito (Demonios en el jardín), lo que le permite hablar a Castellani (1987, p. 145) de que forma parte de una dialéctica de prohibiciones y tentaciones en "una situación de poder, que fundamenta toda infancia, educación y sociedad”. Ese displacer de la comida es el mismo del rito iniciático que ha de pasar Tatín con el imperativo de comer callos (Camada negra), lo que viene representado en dos comidas: en la primera no acepta la exigencia de la Madre ("He dicho que hasta que no se coma los callos no se sienta en mi mesa”) y se levanta de la mesa; en la segunda, pasa por el mal trago una vez vivido el bautismo de fuego en el grupo fascista, el cual brinda por el nuevo miembro tras haber superado la prueba de iniciación.

Compartir la comida representa, preludia o afianza una relación de confianza, familiar o amorosa entre personas con distintos grados de proximidad o parentesco. Me refiero a la del desconocido profesor de Habla, mudita invitado por la abuela a las sopas de ajo y pimentón, la que inicia la perversa relación de Tatín con Rosa (Camada negra), la de Juan y el guerrillero Atilano en la copa del árbol (El corazón del bosque), la compartida por Luis y el oso en el proceso educativo (Feroz), la cena de Rosa con don Pedro tras ser rescatada ella de la comisaría (La mitad del cielo) y la que elaboran juntos la pareja protagonista de Todos estamos invitados; en esta última película, la comida en solitario de Francesca preludia la soledad que le llegará con el asesinato de su pareja y la nueva amenaza que se cierne sobre ella. En Feroz la comida compartida por los

13 El director indica que "se trata de una sugerencia que se hace al espectador para que rememore los tabúes, mandatos y ascos de la infancia ritualizada. No se puede separar el rito de la infancia. La entrada en la edad de la razón está acompañada siempre por el dolor de la pérdida del rito y el deseo de destruir ese rito, una dialéctica sentimental." (La Calle, 157, 24-30 marzo 1981, citado por Castellani, 1987, p. 145). 
cazadores junto al fuego vivificador ha tenido lugar a pie de un árbol, reforzando la fecundidad de ese arquetipo.

El placer gastronómico también está presente en algunos casos, particularmente en la figura de don Pedro (La mitad del cielo) que valora la comida de Rosa contrapuesta a la de sus cuñadas, con quienes vive- más por su elaboración que por la calidad de la materia prima, pues se trata de arroz con leche y casquería ${ }^{14}$; con ello establece una relación afectiva con cierta tensión sexual. En una secuencia, la delectación de ingerir el arroz con leche se refuerza en don Pedro con el placer sensual de ver a Rosa dando el pecho al bebé y en otra este Jefe de Abastos jadea como en un coito al masticar. En Cosas que dejé en La Habana (1997), las tres hermanas cubanas llegadas a Madrid tienen una comida con otras dos mujeres donde se plantea la importancia de saber comer: "lo primero que hay que educar cuando uno llega a otro país es el paladar”.

\section{Conclusiones}

Hemos podido constatar el trasfondo fenoménico de raíz religiosa en un cineasta español no especialmente marcado por su educación en una sociedad impregnada de nacionalcatolicismo. La atracción por elementos naturales o figuras con una tradición notable en la mitología y frecuente valor alegórico es muy relevante en el árbol y el bosque, el arquetipo de la Madre nutricia y los rituales de alimentación. Como queda dicho, estas tres formas poseen una interconexión fuerte en esta filmografía, hasta el punto de que configuran un sustrato con valor semiótico perfectamente interpretable según categorías de la fenomenología de las religiones. Ello nos permite inferir que, en esta perspectiva, el cine de Gutiérrez Aragón se puede comprender globalmente desde el paganismo de tipo animista o panteísta -en términos tradicionales- o cierto ecologismo espiritualista de sacralización de la Naturaleza, en una aproximación más actual. Esto es, no se trata de un cine de preocupaciones religiosas ni siquiera hay en él aproximaciones relevantes al hecho religioso o al cristianismo en particular, de

14 Román Gubern (en Heredero, ed., 2004, p. 112) llama la atención: "Esta función nutricia [desarrollada por Rosa en la casa de don Pedro] adelanta la importancia que tendrán en La mitad del cielo las viandas, el circuito alimentario y los ritos gastronómicos”. 
ahí la calificación de pagano en cuanto opuesto al catolicismo referencial en el marco de la sociedad española.

\section{Referencias bibliográficas}

Castellani, J.-P. (1987). La nourriture chez Manuel Gutiérrez Aragón: représentation et role dans Demonios en el jardín. Hispanística XX, 5, 137145 .

Eliade, M. (1981). Tratado de historia de las religiones: Morfología y dialéctica de lo sagrado. Madrid: Cristiandad.

Frazer, J. G. (2011). La rama dorada: magia y religión. Madrid: Fondo de Cultura Económica.

Gómez Gómez, A. (2013). El bosque físico y metafísico en el corazón de Manuel Gutiérrez Aragón. En P. Poyato (Ed.), Paisajes del cine rural español (pp. 77-104). Córdoba: Diputación de Córdoba.

Gómez Gómez, A. (2019). El paisaje y su poder transformador. En M. Le CorreCarrasco, Ph. Merlo-Morat \& J. L. Sánchez Noriega (Ed.), Manuel Gutiérrez Aragón. Mitos, Religiones y Héroes (pp. 51-64). Lyon: Grimh.

Heredero, C. F. (1998a). Cuentos de magia y conocimiento. El cine de Manuel Gutiérrez Aragón. Madrid: Alta Films.

Heredero, C. F. (1998b). Historias de vida y ficción. El cine según Manuel Gutiérrez Aragón. Huesca: Festival de Cine de Huesca.

Heredero, C. F. (Ed.). (2004). Manuel Gutiérrez Aragón. Las fábulas del cronista. Madrid: Iberautor y Ocho y Medio.

Juan Payán, M. \& López, J. L. (1985). Manuel Gutiérrez Aragón. Madrid: Ediciones JC.

Martínez Torres, A. (1992). Conversaciones con Manuel Gutiérrez Aragón. Madrid: Fundamentos.

Molina Foix, V. (2003). Manuel Gutiérrez Aragón. Madrid: Cátedra.

Neumann, E. (2009). La Gran Madre. Una fenomenología de las creaciones femeninas de lo inconsciente. Madrid: Trotta.

Sánchez Noriega, J. L. Alimentos y rituales de comensalidad en el cine de Manuel Gutiérrez Aragón. En M. Le Corre-Carrasco, Ph. Merlo-Morat y J. L. Sánchez Noriega (Ed.), Manuel Gutiérrez Aragón. Mitos, Religiones y Héroes (pp. 135-150). Lyon: Grimh.

Talens, J. \& Zunzunegui, S. (Eds.). (2007). Contracampo: ensayos sobre teoría e historia del cine. Madrid: Cátedra. 